\title{
How Fast Foods Impact Coronary Artery Disease Incidence: A Cross-Sectional Study
}

\author{
Khudayenoor, Ayesha Shaheen, Aimen Fatima, Zohaib Saleem, Hafeez Arshad, Tayyab Mumtaz \\ Khan, Shahrukh Khan, Bilal Sharif and Madeeha Mumtaz
}

\section{ABSTRACT}

Coronary artery disease (CAD) is a very ordinary health problem around the globe. CAD is affected by various factors like diabetes, obesity, smoking, gender, and diet. However, the association of CAD with diet is understudied in our region that's why our study was aimed to evaluate the effect of diet on CAD incidence. This cross-sectional study was completed among local population of Rawalpindi, Pakistan in almost 6 months from November 2020 to April 2021. People were taken in our study via set criteria. Data was collected by self-structured proforma. Data analysis was performed by applying IBM SPSS version 25. Descriptive statistics were applied for quantitative variables. Statistical tests like Chi-square test and Spearman correlation analysis were applied to know the association, direction, and strength of study variables. Our current study displays overall high prevalence CAD $(17.48 \%)$ among study population. Mean value of age for study participants was 45.42 with $S D$ of \pm 8.01 years. Prevalence of CAD was more common among females, faster food eaters and fresh fruit and raw vegetables non-eaters. Gender, fast food, and fresh fruits and vegetables were associated with CHD significantly with p-values $0.030,0.0007$, and 0.0006 respectively. Strength and direction for fast food and CAD association was very strong and positive while for association between fresh fruits and raw vegetables and CAD was very strong and negative with correlation coefficient +0.812 and $\mathbf{- 0 . 8 3 1}$ respectively. In a nutshell, current study indicates high prevalence of CAD especially among females, fast food eaters and fresh fruits and raw vegetables non-eaters. Higher consumption of fast foods leads to higher incidence of CAD and vice versa while higher consumption of fresh fruits and raw vegetables bring down the incidence of CAD incidence and vice versa. So, we need to create awareness among people about the impact of food on CAD and gender specific interventions for each gender to lower down the CAD incidence.

Keywords: Coronary artery disease, cross sectional, fast foods, impact, incidence.

Submitted : August 29, 2021

Published. : October 14, 2021

ISSN: 2593-8339

DOI: $10.24018 /$ ejmed.2021.3.5.1033

\section{Khudayenoor}

Fazaia Medical College, Pakistan.

A. Shaheen

University of Agriculture Faisalabad, Pakistan.

A. Fatima

Rawalpindi Medical University,

Pakistan.

Z. Saleem

University of Agriculture Faisalabad, Pakistan.

H. Arshad

University of Agriculture Faisalabad, Pakistan.

T. M. Khan*

Rawalpindi Medical University, Pakistan.

(e-mail:tayyab.mkhan98@gmail.com) S. Khan

University of Veterinary and Animal Sciences, Pakistan.

B. Sharif

Rawalpindi Medical University, Pakistan.

M. Mumtaz

Lahore College for Women

University, Pakistan.

*Corresponding Author

\section{INTRODUCTION}

Coronary artery disease (CAD) is very common and third most prevalent killer all over the world [1]. Its incidence is still rising day by day because of our changing lifestyles. Various research that was conducted in different countries like United States of America, Russia, China, and Saudi Arabia have manifested high prevalence of $\mathrm{CAD}$ among their respective population [2]-[5]. In Pakistan, prevalence of CAD is also high according to a study that was conducted at Karachi [6].

CAD is affected by many factors like gender, age, hypertension (HTN), obesity, diabetes, smoking and diet. Gender difference has been noted in the prevalence of CAD. A study has shown that female suffer more commonly from CAD while other reported higher incidence of CAD among males. In literature, various studies have shown that with increase of age, CAD incidence also goes up. HTN, obesity diabetes and smoking also known culprits in the causation of CAD [6]-[10].

Along with other factors that affect CAD prevalence, importance of diet could not be ignored as the junk foods consumption is increasing day by day. In literature, different factors like taste, early digestion, easy availability have been reported that lead to higher consumption of fast foods [11][13]. Various studies in literature reported higher incidence of CAD among fast food eaters while studies have also shown that we could avoid CAD by eating fresh fruits and raw vegetables daily [14]-[17]. Diet is very important factor for CAD as it's a very important factor that could be modified by all people very easily. Therefore, serious measures should be taken to induce people to eat healthy foods and avoid unhealthy foods.

Besides, numerous research that have been conducted around the globe to show the impact of diet on CAD incidence [14]-[16]. In literature, number of studies that could give knowledge regarding the effect of diet on CAD in 
Pakistan, were few. Therefore, in the presence of few studies that could displays that how food influences CAD at our national and specifically, at the regional level, our study was set with aim to know how diet affects CAD incidence among regional and general population of Rawalpindi, Pakistan. In case, our study result shows that CAD is impacted by diet then by implementation of proper measures for diet planning, we would bring down the incidence of CAD among Rawalpindi population.

\section{MATERIAL AND METHODS}

\section{A. Study Design and Study Population}

We used comparative cross-sectional study design in this study. This study was done among all inclusive community of Rawalpindi, Pakistan in almost 6 months from November 2020 to April 2021. 143 willing participants whose age was above 40 years but not more than 60 were recruited in study in accordance to established rules for inclusion and exclusion. Those people whose age was not within our set models were excluded from study. We applied one self-structured proforma for data collection. Then, we delivered important information in regard to the objectives of study. In following step, we took verbal consent from all members for participating in our present research project. Proformas were filled by meet and required assessments of all selected members.

\section{B. Assessment of Characteristics of Study Population and Diagnosis of Coronary Artery Disease}

We used a self-planned proforma to acquire essential information regarding the demographic elements like, age and gender. Subsequent to socioeconomic information we collected data about the coronary artery disease (CAD) by asking participants either they are taking medication for coronary heart disease or have history of taking medication in past or not. People who had taking or had history of taking medication were diagnosed as patients of CAD while who were not taking were any medications for CAD were excluded from category of CAD patients.

\section{Assessment of Food Intake}

On used proforma first a question regarding fast food consumption was asked from all participants either they eat fast food or not then frequency levels of two included food groups consumption were recorded on proforma in last month and these food groups comprised of Fresh foods like, fruits and raw vegetables, and Fast foods including pizza, burgers, fried chicken, nuggets, shawarma, sandwiches, and fried chips. We made four consumption frequency levels for each of two contained foods as zero frequency, low frequency, moderate frequency, and high frequency. These levels were made by knowing the eating frequency of individual group of food per week during last month. Intake of particular group of food for not even for single time was viewed as zero frequency, once or less than one a week was taken as low frequency level, 2-3times a week or 4-6times a week was viewed moderate frequency level and once a day and more one times per day was regarded high frequency level of that particular food group. Fast foods were considered poor quality foods, while fruits and vegetables were taken as good quality healthy foods.

\section{Data Analysis}

IBM SPSS version.25 was utilized for data analysis. Descriptive statistics were applied to summarize study quantitative variables. Chi square analysis was used, to determine the association first between CAD and gender then between fast food and CAD, in the end between fresh fruits and raw vegetables and CAD. Subsequently, rho spearman correlation to know the direction and strength of association $\mathrm{CAD}$ and consumption frequency levels of foods. We considered p-value of less than 0.05 statistically significant.

\section{RESULTS}

From total of 143 people who were participants of our present study 82 (57.34\%) were females and 61 (42.66\%) were males. For recruited people in study mean of age, was 45.42 with SD of \pm 8.01 years. In present study 25 (17.48\%) people had CAD while $118(42.52 \%)$ had not CAD.

Fig. 1 manifests the gender wise distribution of female and male participants in current study.

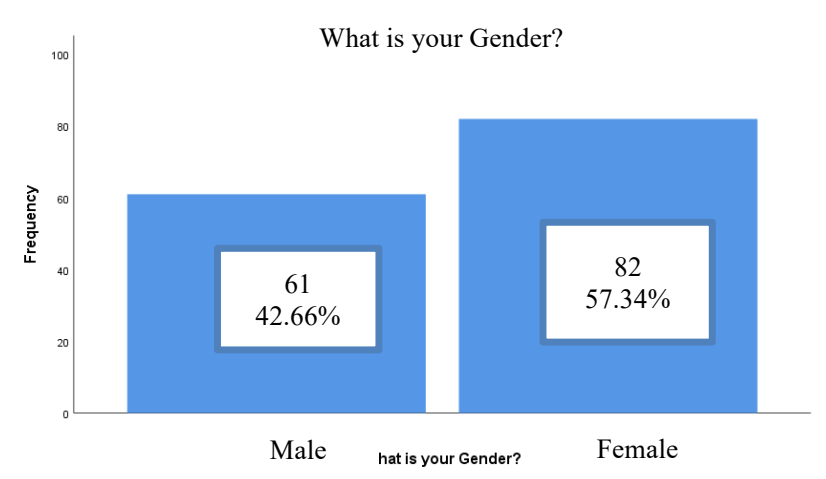

Fig. 1. Distribution of study population according to gender.

Table I shows that prevalence of CAD was more common among females, fast food eaters, and fresh fruits and vegetables non-eaters in comparison to males, fast food noneaters and fresh fruits and vegetables eaters. Likewise, it also shows that gender, fast food and fresh fruits and vegetables were associated with CAD. It was assessed by Chi-square analysis.

TABLE I: STUDY POPULATION PARAMETERS ALONG WITH THEIR CROSSTABULATION WITH STUDY VARIABLES AND CHI-SQUARE ANALYSIS

\begin{tabular}{|c|c|c|c|c|}
\hline \multicolumn{5}{|c|}{ Cross-Tabulation and chi-square analysis } \\
\hline \multirow{2}{*}{\multicolumn{2}{|c|}{ Parameter }} & \multicolumn{2}{|c|}{ CAD Status } & \multirow{3}{*}{$\begin{array}{c}\text { Chi-Square } \\
\text { Analysis } \\
\text { p-value } \\
\end{array}$} \\
\hline & & \multirow{2}{*}{ Patient } & \multirow{2}{*}{ Normal } & \\
\hline Total & & & & \\
\hline Gender & $\begin{array}{c}\text { Women } \\
(\mathrm{n}=82) \\
\text { Men } \\
(\mathrm{n}=61)\end{array}$ & $\begin{array}{c}18 \\
(21.95 \%) \\
7(11.47 \%)\end{array}$ & $\begin{array}{c}64 \\
(78.05 \%) \\
54 \\
(88.53 \%)\end{array}$ & 0.030 \\
\hline $\begin{array}{c}\text { Fast Food } \\
\text { Consumption } \\
\text { Status }\end{array}$ & $\begin{array}{c}\text { Eater } \\
(\mathrm{n}=130) \\
\text { Non-Eater } \\
(\mathrm{n}=13)\end{array}$ & $\begin{array}{c}24 \\
(18.46 \%) \\
01(7.69 \%)\end{array}$ & $\begin{array}{c}106 \\
(81.54 \%) \\
12 \\
(92.31 \%)\end{array}$ & 0.0007 \\
\hline $\begin{array}{l}\text { Fresh Fruits } \\
\text { and Raw }\end{array}$ & $\begin{array}{c}\text { Eater } \\
(n=119)\end{array}$ & $6(5.04 \%)$ & $\begin{array}{c}113 \\
(94.96 \%)\end{array}$ & \\
\hline $\begin{array}{c}\text { Vegetables } \\
\text { Consumption } \\
\text { Status }\end{array}$ & $\begin{array}{c}\text { Non-Eater } \\
(n=24)\end{array}$ & $\begin{array}{c}19 \\
(79.16 \%)\end{array}$ & $\begin{array}{c}5 \\
(20.84 \%)\end{array}$ & 0.0006 \\
\hline
\end{tabular}


Table II displays the direction and strength of association between food groups and CAD along with percentages of consumers according to food consumption frequency levels. Positive correlation coefficient for fast food and CAD shows that with the increase of fast-food consumption, CAD incidence goes up and vice versa, while negative correlation coefficient for fresh fruits and raw vegetables shows with the rise of this food group consumption, CAD prevalence goes down and vice versa.

TABLE II: SPEARMAN's CORRELATION FOR CAD AND FOOD GROUPS ALONG WITH PERCENTAGES OF FOOD CONSUMERS OF INCLUDED FOOD GROUPS ACCORDING TO THEIR FREQUENCY LEVELS

\begin{tabular}{ccccc}
\hline \hline \multirow{2}{*}{$\begin{array}{c}\text { Kinds of } \\
\text { Food }\end{array}$} & $\begin{array}{c}\text { Frequency } \\
\text { Levels of } \\
\text { Food } \\
\text { Consumption }\end{array}$ & $\begin{array}{c}\text { Percentages } \\
\text { of Food } \\
\text { Consumers }\end{array}$ & $\begin{array}{c}\text { Spearman's Correlation } \\
\text { coefficient (r) }\end{array}$ & p-value \\
\hline \hline \multirow{5}{*}{ Fast Food } & High & $35.34 \%$ & & \\
& Moderate & $43.21 \%$ & 0.812 & 0.0007 \\
& Low & $12.23 \%$ & & \multirow{2}{*}{0.0006} \\
Fruits and & Zero & $9.22 \%$ & & \\
Raw & High & $21.98 \%$ & & \\
Vegetables & Moderate & $28.90 \%$ & & \\
& Low & $32.77 \%$ & & \\
\hline \hline
\end{tabular}

Our study results indicate overall high prevalence of coronary heart disease among study participants. CAD is more prevalent in women as compared to women. Fast foods consumption leads to higher incidence of CAD whereas, fresh fruits and raw vegetables utilization brings down the prevalence of CAD.

\section{Discussion}

Our study provides very significant information regarding prevalence of CAD among general population of Rawalpindi, Pakistan and how diet influences the incidence of CAD among study population. In the beginning of data analysis, we noted the value of quantitative variables mean age of study population which was 45.42 with $\mathrm{SD}$ of \pm 8.01 years. Prevalence of CAD was $17.48 \%$. A study that was also conducted in Pakistan reported similar finding with CAD prevalence of $17.50 \%$ [18]. After noting quantitative variables, we observed that $\mathrm{CAD}$ was more common among females as compared to males. This finding of study was supported by a study that was conducted in Pakistan as well [18]. Another study showed that CAD incidence are higher among males while more severe in females [6]. Gender was associated with CAD significantly with $p$-value of 0.030 via Chi-square test. In next step of data analysis, we noticed that CAD was positively and strongly (correlation coefficient = +0.812 ) linked with fast foods which means that with the increase of fast-food consumption, the incidence of CAD was raises and vice versa. Similar results have been displayed in researches that were conducted at Denmark and United States Of America [14], [15]. P-value for association between fast food and CAD was 0.0007 . Association between fresh fruits and raw vegetables and $\mathrm{CAD}$ was negative and strong (correlation coefficient $=-0.831$ ) which means that these foods are helpful in bringing down the incidence of CAD. Lower incidence of CAD among these foods eaters has been also reported in literature by a study that was conducted in
United States of America [16], [17]. P-value for association between fresh fruits and raw vegetables and CAD was 0.0006. Association between foods and CAD was assessed by Chi-square analysis while direction and strength were evaluated by Spearman correlation in cases of both type of foods. Various reasons have been manifested in literature, that leads to higher consumption of junk food among people in contrast to healthy foods. These reasons include taste, easy digestion, mental disease and easy availability [12], [13]. Higher incidence of CAD among fast food eaters could be due their higher fat content which induce damage to endothelium of blood vessels, atheroma formation in the blood vessels and eventually blockage of blood vessels which leads to ischemia and in the end necrosis of organ that get supply from that blood vessels. In literature, study that was conducted in Iran has supported this statement that fatty diet leads to CAD [7]. It could be directly or indirectly via obesity which leads to HTN and then CAD indirectly [19]. Various studies have shown that salty food leads to hypertension, and consequently hypertension causes CAD. As fast foods are also enriched in salt content, so this could be another reason of higher incidence of CAD among fast food eaters [20]. Although present study has limitations as its design is crosssectional, however, this study still has very significance as it has highlighted very prevalent issue. As far as, we know, the extent we know, present study is the only that has reported CAD prevalence and diet impact on it among local population of Rawalpindi, Pakistan. Current study proposes that government should conduct session for the awareness of people about the role of diet, that how diet affects the health of general population, so that could avoid unhealthy diets and eat only healthy and balanced diet. More research is required to know causal link of CAD and diet at regional and national level.

\section{CONCLUSION}

Our study demonstrates overall high prevalence of coronary artery disease in study population. Prevalence of CAD was more common among women, junk food eaters, and fresh fruits and vegetables non-eaters in contrast to men, junk food non-eaters and fresh fruits and vegetables eaters and these differences were significant statistically. So, by applying suitable intercessions and awareness programs regarding healthy diet we could bring down the incidence of coronary artery disease.

\section{ACKNOWLEDGEMENT}

We (the co-first author, the corresponding author Dr. Tayyab Mumtaz Khan, and all co-authors) thank all respected participants, who participated in this research).

\section{REFERENCES}

[1] P.A. McCullough, "Coronary artery disease," Clinical Journal of the American Society of Nephrology 2(3):611-6, 2007.

[2] G. A. Mensah, D. W. Brown, "An overview of cardiovascular disease burden in the United States," Health affairs 26(1):38-48, 2007.

[3] I. S. Petrukhin, E. Y. Lunina, "Cardiovascular disease risk factors and mortality in Russia: challenges and barriers," Public Health Reviews 33(2):436-49, 2011. 
[4] X. Wang, M. Gao, S. Zhou, J. Wang, F. Liu, F. Tian, J. Jin, Q. Ma, X. Xue, J. Liu, Y. Liu, "Trend in young coronary artery disease in China from 2010 to 2014: a retrospective study of young patients $\leq 45$," $B M C$ cardiovascular disorders 17(1):1-8, 2017.

[5] M. M. Al-Nozha, M. R. Arafah, Y. Y. Al-Mazrou, M. A. Al-Maatouq, N. B. Khan, M. Z. Khalil, A. H. Al-Khadra, K. Al-Marzouki, M. A. Abdullah, S. S. Al-Harthi, M. S. Al-Shahid, "Coronary artery disease in Saudi Arabia," Saudi med J 25(9):1165-71, 2004.

[6] T. H. Jafar, Z. Qadri, N. Chaturvedi, "Coronary artery disease epidemic in Pakistan: more electrocardiographic evidence of ischaemia in women than in men," Heart 94(4):408-13, 2008.

[7] Z. N. Hatmi, S. Tahvildari, A. G. Motlag, A. S. Kashani, "Prevalence of coronary artery disease risk factors in Iran: a population-based survey," BMC cardiovascular disorders 7(1):1-5, 2007.

[8] I. Wakabayashi, "Gender differences in cardiovascular risk factors in patients with coronary artery disease and those with type 2 diabetes," Journal of thoracic disease 9(5): E503, 2017.

[9] L. Galiuto, G. Locorotondo, "Gender differences in cardiovascular disease," Journal of Integrative Cardiology 1(1):20-2, 2015.

[10] J. Tuomilehto, "Impact of age on cardiovascular risk: implications for cardiovascular disease management," Atherosclerosis Supplements 5(2):9-17, 2004

[11] T. M. Khan, S.Bibi, S. T. Rasool, M. Jamil, S. Khan, H. Shafique, S. U. Jafri, H. Ishfaq, S. Salamat, U. F. Iqbal, H. Amjad, "Impact of Depression on Food Consumption Frequency among Medical Students of Rawalpindi Medical University, Pakistan," European Journal of Medical and Health Sciences 2(6), 2020.

[12] T. M. Khan, S. Bibi, T. Shoaib, E. Shoaib, A. Bibi, H. Sajid, S. Khan, A. Sohail, J. Akram, M. Naseer, M. Mumtaz, "Perceived Stress and Food Consumption Frequency among Medical Students of Rawalpindi Medical University, Pakistan," European Journal of Medical and Health Sciences 2(6), 2020.

[13] C. Liu, B. Xie, C.P. Chou, C. Koprowski, D. Zhou, P. Palmer, P. Sun, Q. Guo, L. Duan, X. Sun, C. A. Johnson, "Perceived stress, depression and food consumption frequency in the college students of China Seven Cities," Physiology \& behavior 92(4):748-54, 2007.

[14] S. Stender, J. Dyerberg, A. Astrup, "Fast food: unfriendly and unhealthy," International Journal of Obesity 31(6):887-90, 2007.

[15] L. E. Cahill, A. Pan, S. E. Chiuve, Q. Sun, W. C. Willett, F. B. Hu, E. B. Rimm, "Fried-food consumption and risk of type 2 diabetes and coronary artery disease: a prospective study in 2 cohorts of US women and men," The American journal of clinical nutrition 100(2):667-75, 2014.

[16] C. B. Esselstyn, "A plant-based diet and coronary artery disease: a mandate for effective therapy," Journal of geriatric cardiology: JGC 14(5):317, 2017.

[17] P. Tuso, S. R. Stoll, W. W. Li, "A plant-based diet, atherogenesis, and coronary artery disease prevention," The Permanente Journal 19(1):62, 2015.

[18] F. Zubair, S. K. Nawaz, A. Nawaz, H. Nangyal, N. Amjad, M. S. Khan, "Prevalence of cardiovascular diseases in Punjab, Pakistan: a crosssectional study," Journal of Public Health 26(5):523-9, 2018.

[19] J. Akram, H. R. Rehman, F. Muneer, S. Hassan, R. Fatima, T. M. Khan, M. Khizar, S. Tahir, M. Asim, M. Shabbir, S. Asif, "Hypertension and Obesity: A Cross-Sectional Study," European Journal of Medical and Health Sciences 3(4), 90-94, 2021.

[20] Y. Erdem, M. Arici, B. Altun, C. Turgan, S. Sindel, B. Erbay, U. Derici, O. Karatan, E. Hasanoglu, S. Caglar, "The relationship between hypertension and salt intake in Turkish population: SALTURK study," Blood pressure 19(5):313-8, 2010.

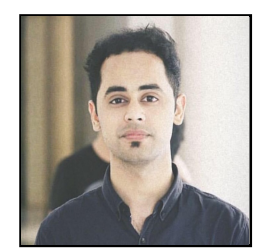

DR. Tayyab Mumtaz Khan

Place and date of birth: Lahore, Pakistan, 23-31996.

Educational background: BSC, MBBS. Affiliation: Rawalpindi Medical University, Rawalpindi, Pakistan. 